\title{
Comparison of the 16S/23S Ribosomal Intergenic Regions of "Candidatus Liberobacter asiaticum" and "Candidatus Liberobacter africanum," the Two Species Associated with Citrus Huanglongbing (Greening) Disease
}

\author{
SANDRINE JAGOUEIX, JOSEPH M. BOVE, AND MONIQUE GARNIER* \\ Laboratoire de Biologie Cellulaire et Moléculaire, Institut National de la Recherche Agronomique \\ and Université Victor Ségalen, Bordeaux 2, 33883 Villenave d'Ornon Cedex, France
}

\begin{abstract}
16S/23S intergenic spacer regions from the rRNA operons of two strains of "Candidatus Liberobacter asiaticum" and one strain of "Candidatus Liberobacter africanum" were cloned and sequenced. The intergenic spacers of the two "Candidatus $L$. asiaticum" strains studied are identical and contain the genes for isoleucine tRNA (tRNA ${ }^{\text {Ile }}$ ) and alanine tRNA (tRNA $\left.{ }^{\text {Ala }}\right)$ separated by 11 nucleotides. The intergenic spacer of the "Candidatus $L$. africanum" strain contains only one tRNA gene (tRNA $\left.{ }^{\mathrm{Ala}}\right)$. The level of homology between the intergenic spacers of the two liberobacter species is $79.46 \%$. Ribosomal operons with $16 \mathrm{~S} / 23 \mathrm{~S}$ spacer regions other than those studied might be present in the two "Candidatus Liberobacter" species.
\end{abstract}

Huanglongbing (HLB) (greening) disease is one of the most severe diseases of citrus, occurring in Asian and African countries, in the Arabic Peninsula, and on Madagascar, Reunion, and Mauritius, which are islands in the Indian Ocean $(2,5)$. The agent of the disease is a bacterium which is restricted to the phloem sieve tubes of infected plants. Infection of plants occurs through two psyllid vectors, Diaphorina citri in Asia and Trioza erytreae in Africa $(3,10)$. Today, despite many attempts, the HLB disease bacterium has resisted in vitro cultivation. Recently, we were able to characterize the HLB disease bacterium by cloning its $16 \mathrm{~S}$ rRNA gene (7), as well as genes of the $\beta$ operon $(13,17)$. In this work we showed that the HLB disease bacterium belongs to the alpha subdivision of the Proteobacteria, in which it represents a new genus with two species, one associated with HLB disease in Asia and the other associated with HLB disease in Africa. The designations "Candidatus Liberobacter asiaticum" and "Candidatus Liberobacter africanum" were given to the two species according to the rules established for uncultured organisms (12).

The genes that we cloned and sequenced for taxonomic characterization have been used to develop detection methods, including DNA-DNA hybridization and PCR detection methods $(8,16)$. These methods have allowed the detection and identification of the liberobacter species, but they have not permitted differentiation of the various serotypes which occur in each species $(4,6)$. In order to further characterize the two liberobacter species at the molecular level and to find genomic polymorphism, we cloned and sequenced the intergenic $16 \mathrm{~S}$ / 23S rRNA spacer region known to be highly variable at both the interspecies level and the intraspecies level $(1,9)$.

DNA was extracted as described by Jagoueix et al. (8) from healthy sweet orange (Citrus sinensis) plants or sweet orange plants infected with one of the following liberobacter strains: "Candidatus L. asiaticum" Poona (from India) or Fuzhou (from the People's Republic of China) or "Candidatus L. africanum" Nelspruit (from South Africa). The three strains belong to three different serotypes (4) and have been described

* Corresponding author. Mailing address: Laboratoire de Biologie Cellulaire et Moléculaire, Institut National de la Recherche Agronomique et Université Victor Ségalen, Bordeaux 2, BP 81, 33883 Villenave d'Ornon Cedex, France. previously (6). The $16 \mathrm{~S} / 23 \mathrm{~S}$ intergenic region of each strain was obtained by PCR amplification with primers OI2 and $23 \mathrm{~S} 1$. Primer OI2 was defined on the basis of the $16 \mathrm{~S}$ ribosomal DNA (rDNA) sequence of "Candidatus L. asiaticum" Poona (7) and is located $240 \mathrm{bp}$ upstream of the $3^{\prime} \mathrm{OH}$ end of the $16 \mathrm{~S}$ rDNA. This primer allows differentiation of the three liberobacter strains, since in this region each strain has several characteristic nucleotides. Primer 23S1 was defined at the beginning of the 23S rDNA by comparison with $23 \mathrm{~S}$ rDNA sequences present in the GenBank database. The sequence of 23S1 is $5^{\prime}$ CGC CCT TCT CGC GCT TGA $3^{\prime}$.

The DNA was amplified for 35 cycles with a thermocycler (Perkin-Elmer Cetus) by using the following program: $92^{\circ} \mathrm{C}$ for $40 \mathrm{~s}, 55^{\circ} \mathrm{C}$ for $40 \mathrm{~s}$, and $72^{\circ} \mathrm{C}$ for $90 \mathrm{~s}$. Then the amplified DNA was analyzed on $0.7 \%$ agarose gels, and DNA bands of similar size $(800 \mathrm{bp})$ were observed with all three liberobacter strains

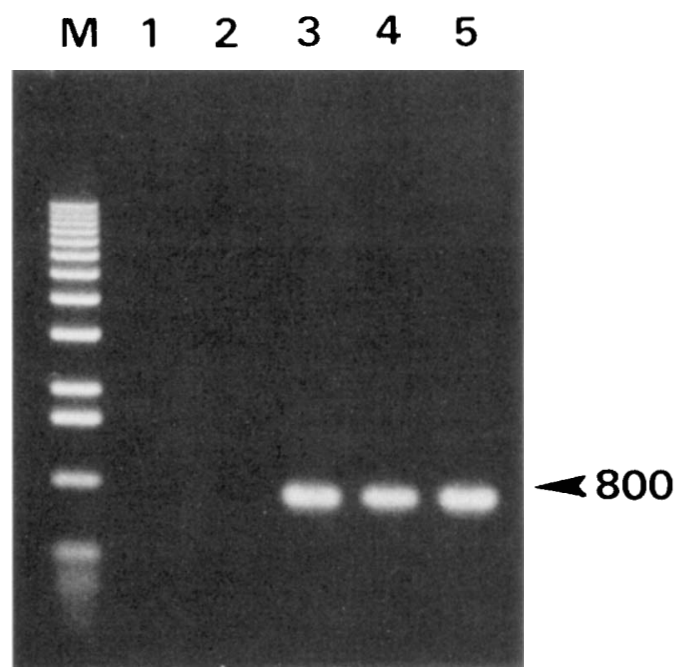

FIG. 1. Agarose gel electrophoresis of DNAs amplified with primers OI2 and 23S1 from water (lane 1), healthy citrus midrib extracts (lane 2), and citrus midrib extracts infected with "Candidatus L. africanum" Nelspruit (lane 3) or "Candidatus L. asiaticum" Poona (lane 4) or Fuzhou (lane 5). Lane M contained a 1-kb ladder (Gibco BRL). 


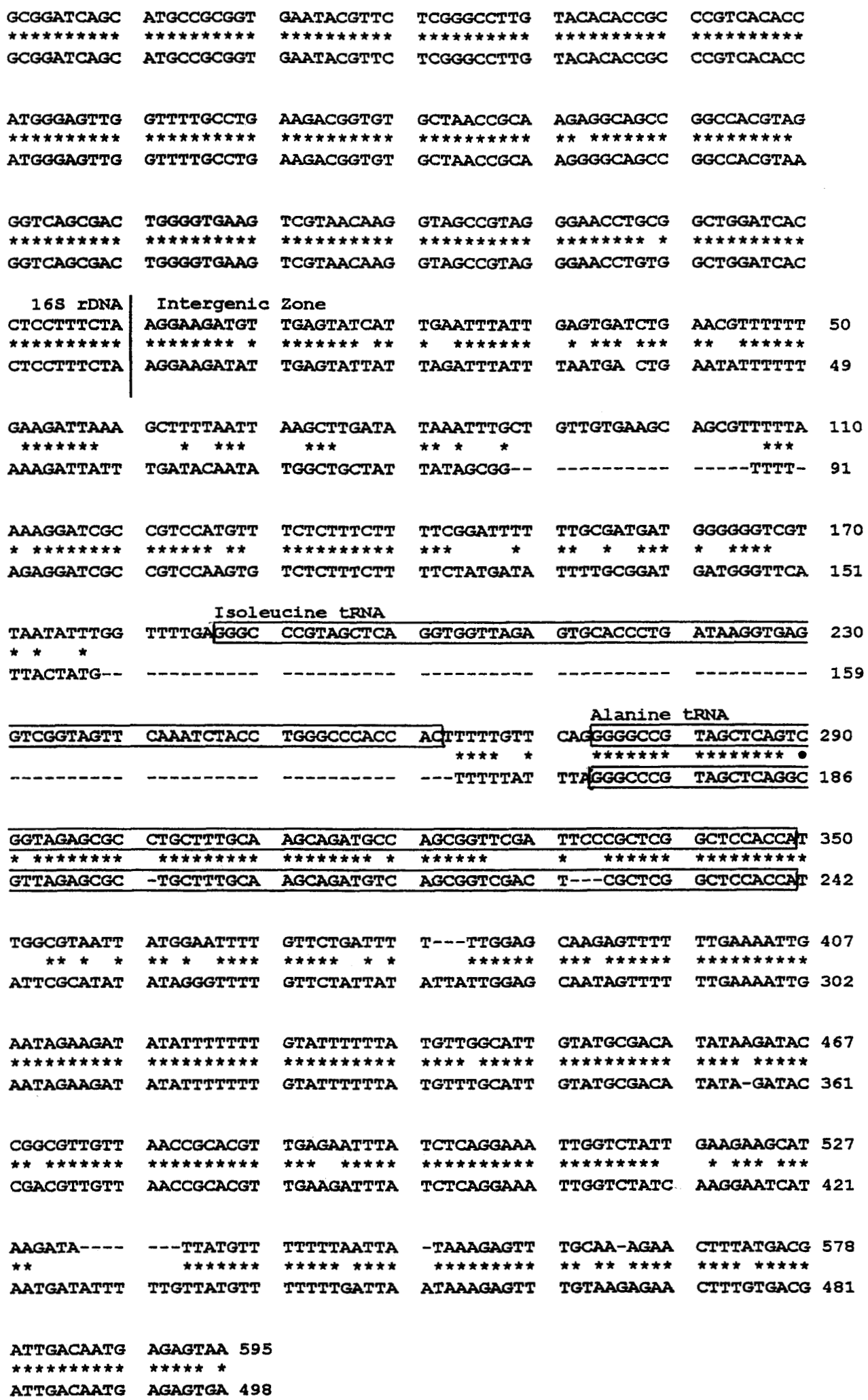

FIG. 2. Alignment of the sequences of the $3^{\prime} \mathrm{OH}$ ends of $16 \mathrm{~S}$ rDNAs and the $16 \mathrm{~S} / 23 \mathrm{~S}$ intergenic spacer regions of "Candidatus $\mathrm{L}$. asiaticum" (upper line) and "Candidatus L, africanum" (lower line). tRNA ${ }^{\mathrm{Il}}$ and tRNA ${ }^{\mathrm{Ala}}$ are enclosed in boxes. Asterisks indicate identical nucleotides. 
tested (Fig. 1, lanes 3 through 5). No amplification occurred when water was used in place of plant DNA (Fig. 1, lane 1) or when DNA extracted from healthy citrus leaves was used (Fig. 1, lane 2) as primer OI2 is highly specific for the liberobacters and does not amplify plant DNA. The amplified DNA from each of the three liberobacter strains was cloned and sequenced by the method of Sanger et al. (14) with a T7 polymerase kit from Pharmacia. Sequencing was done on three different clones. The sequences of "Candidatus L. asiaticum" (Poona) and "Candidatus L. africanum" (Nelspruit) are shown in Fig. 2.

A comparison of the sequences of the "Candidatus L. asiaticum" strains from India and the People's Republic of China showed that the intergenic region was identical in the two strains and was $595 \mathrm{bp}$ long. In contrast, the intergenic region of "Candidatus L. africanum" was different and was only 498 bp long. In addition, two putative tRNA genes separated by 11 nucleotides, tRNA ${ }^{\text {Ile }}$ (nucleotides 186 to 262 ) and tRNA ${ }^{\text {Ala }}$ (nucleotides 274 to 349 ), were identified in the intergenic region of "Candidatus L. asiaticum," while only one tRNA gene (tRNA $^{\text {Ala }}$; nucleotides 170 to 241 ) was present in the intergenic region of "Candidatus $\mathbf{L}$. africanum." The level of homology of the entire $16 \mathrm{~S} / 23 \mathrm{~S}$ intergenic regions of "Candidatus L. asiaticum" and "Candidatus L. africanum" was $79.46 \%$, and the level of homology of the two tRNA ${ }^{\text {Ala }}$ regions was $87.8 \%$. The lengths of the intergenic regions of other bacteria vary between 50 and 906 bp (11). In many cases, these regions contain genes for one or two tRNAs. However, in certain low-G $+\mathrm{C}$-content gram-positive bacteria, such as Clostridium perfringens and many mollicutes species, as well as several high-G+C-content gram-positive bacterial species, such as $M y$ cobacterium, Frankia, Streptomyces, and Bifidobacterium species, no tRNA genes are present $(9,15)$. Interestingly, tRNA ${ }^{\text {Ile }}$ and tRNA ${ }^{\text {Ala }}$ were also identified in the $16 \mathrm{~S} / 23 \mathrm{~S}$ intergenic region of Bartonella bacilliformis, a bacterium belonging to the $\alpha 2$ subgroup of the Proteobacteria, the cluster closest to the liberobacters $(7,11)$.

Because the HLB disease liberobacters are not available in culture, it is difficult to determine the number of rRNA operons present in their bacterial genomes. However, results based on Southern blot analyses of restricted total DNAs from healthy and liberobacter-infected plants probed with $16 \mathrm{~S}$ rDNA suggest that each liberobacter species is likely to have two rRNA operons (data not shown). In addition, a large ribosomal operon similar to that of "Candidatus L. asiaticum" seems to be present in "Candidatus L. africanum," as the band on the gel shown in Fig. 1 was at the same position for the two species. By analogy with the "Candidatus L. asiaticum" operon, such a large "Candidatus L. africanum" operon could contain tRNA $^{\text {Ile }}$ in addition to tRNA ${ }^{\text {Ala }}$. To investigate this possibility, primer TRNI (5' GCC CAG GTA GAT 3'), which was designed by using a conserved part of tRNA ${ }^{\text {Ile }}$ (stem positions 435 to 446 [Escherichia coli numbering]), was used in combination with primer OI4 (5' GAA GTC GTA ACA AGG 3') located in the 16S rDNA to amplify DNAs extracted from citrus plants infected with. "Candidatus L. asiaticum" and "Candidatus L. africanum." The amplified products, as visualized on $0.7 \%$ agarose gels after 35 PCR cycles (each consisting of $92^{\circ} \mathrm{C}$ for $40 \mathrm{~s}, 48^{\circ} \mathrm{C}$ for $40 \mathrm{~s}$, and $72^{\circ} \mathrm{C}$ for $90 \mathrm{~s}$ ), are shown on Fig. 3. A 350-bp DNA fragment (the expected size) was obtained with plants infected with "Candidatus L. asiaticum" (Fig. 3, lane 3), but no amplification was seen in the case of "Candidatus L. africanum" (lane 4). This suggests that tRNA ${ }^{\text {Ile }}$ is not present in "Candidatus L. africanum." However, we cannot rule out the possibility that the sequence of the putative

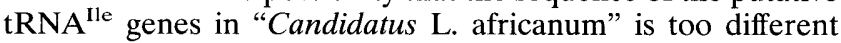

\section{M $1122 \quad 3 \quad 4$}

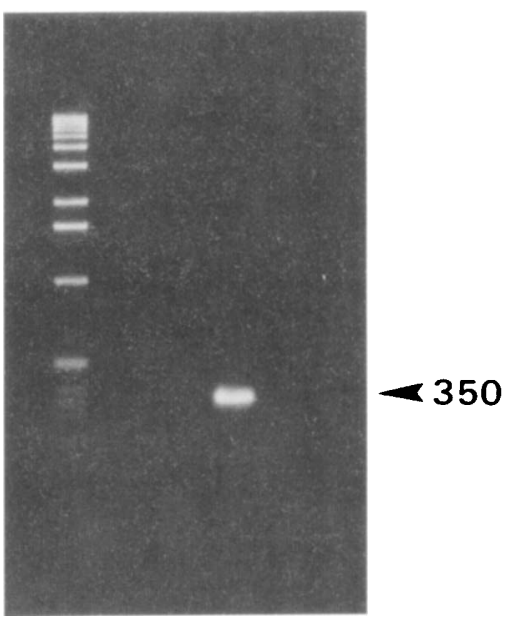

FIG. 3. Agarose gel electrophoresis of DNAs amplified with primers OI4 and TRN1 from water (lane 1), healthy citrus midrib extracts (lane 2), and citrus midrib extracts infected with "Candidatus L. asiaticum" Poona (lane 3) or "Candidatus L. africanum" Nelspruit (lane 4). Lane M contained a 1-kb ladder (Gibco BRL)

from that of "Candidatus L. asiaticum" to be amplified with primer TRN1. This possibility is not unlikely as we know that the tRNA ${ }^{\text {Ala }}$ sequences of the two liberobacter species exhibit only $87.8 \%$ homology.

At this stage, we have not been able to clone and sequence the larger operon of "Candidatus L. africanum." The possibility that this operon is identical to that of "Candidatus L. asiaticum" seems unlikely as no amplification occurred with TRN1. Also, we do not know if a short operon similar to the one sequenced in "Candidatus L. africanum" is present in "Candidatus L. asiaticum." New PCR strategies will have to be developed in order to clone these putative operons.

The sequence variability of the $16 \mathrm{~S} / 23 \mathrm{~S}$ intergenic region is useful for differentiating not only species but also strains within species (9). In the case of the intergenic $16 \mathrm{~S} / 23 \mathrm{~S}$ regions of "Candidatus L. asiaticum" Poona and Fuzhou, 100\% homology was observed, even though these two strains belong to different serotypes and were isolated from geographically distant areas. This probably indicates that in the genus "Candidatus Liberobacter," the $16 \mathrm{~S} / 23 \mathrm{~S}$ region does not vary much within a given species. Hence, monoclonal antibodies remain the only reagents that allow identification of liberobacter strains within a given species.

Nucleotide sequence accession numbers. The DNA nucleotide sequences of "Candidatus L. asiaticum" Poona and "Candidatus L. africanum" Nelspruit have been deposited in the GenBank database under accession numbers U61359 and U61360, respectively.

The research on citrus HLB disease was supported in part by CIRAD-FLHOR.

\section{REFERENCES}

1. Barry, T, G. Colleran, M. Glennon, L. K. Dunican, and F. Gannon. 1991. The $16 \mathrm{~S} / 23 \mathrm{~S}$ ribosomal spacer region as a target for DNA probes to identify eubacteria. PCR Methods Appl. 1:51-56.

2. Bové, J. M., and M. Garnier. 1984. Citrus greening and psylla vectors of the disease in the Arabic Peninsula, p. 109-114. In S. M. Garnsey, L. W. Timmer, and J. A. Dodds (ed.), Proceedings of the 9th Conference of the International Organization of Citrus Virologists. Department of Plant Pathology, University of California, Riverside.

3. Capoor, S. P., D. G. Rao, and S. M. Viswanath. 1967. Diaphorina citri 
Kuway., a vector of greening disease of citrus in India. Indian J. Agric. Sci. 37:572-576.

4. Gao, S. J., M. Garnier, and J. M. Bové. 1993. Production of monoclonal antibodies recognizing most Asian strains of the greening BLO by in vitro immunization with an antigenic protein purified from the BLO, p. 244-249. In P. Moreno, J. V. Da Graça, and L. W. Timmer (ed.), Proceedings of the 12th Conference of the International Organization of Citrus Virologists. Department of Plant Pathology, University of California, Riverside.

5. Garnier, M., and J. M. Bové. 1993. Citrus greening disease and the greening bacterium, p. 212-219. In P. Moreno, J. V. Da Graça, and L. W. Timmer (ed.), Proceedings of the 12th Conference of the International Organization of Citrus Virologists. Department of Plant Pathology, University of California, Riverside.

6. Garnier, M., G. Martin-Gros, and J. M. Bové. 1987. Monoclonal antibodies against the bacterial-like organism associated with citrus greening disease. Ann. Microbiol. (Inst. Pasteur) 138:639-650.

7. Jagoueix, S., J. M. Bové, and M. Garnier. 1994. The phloem-limited bacterium of greening disease of citrus is a member of the $\alpha$ subdivision of the proteobacteria. Int. J. Syst. Bacteriol. 44:379-386.

8. Jagoueix, S., J. M. Bové, and M. Garnier. 1996. PCR detection of the two liberobacter species associated with greening disease of citrus. Mol. Cell. Probes 10:43-50.

9. Leblond-Bourget, N., H. O. Philippe, I. Mangin, and B. Decaris. 1996. 16S rRNA and $16 \mathrm{~S}$-to-23S internally transcribed spacer sequence reveals interand intraspecific Bifidobacterium phylogeny. Int. J. Syst. Bacteriol. 46:102and 111 .

10. McLean, A. P. D., and P. C. J. Oberholzer. 1965. Citrus psylla, a vector of the greening disease of sweet orange. S. Afr. J. Agric. Sci. 8:297-298.

11. Minnick, M. F., J. C. Strange, and K. F. Williams. 1994. Characterization of the 16S-23S rRNA intergenic spacer of Bartonella bacilliformis. Gene 143: 149-150.

12. Murray, R. G. E., and K. H. Schleifer. 1994. Taxonomic notes: a proposal for recording the properties of putative taxa of procaryotes. Int. J. Syst. Bacteriol. 44:174-176.

13. Planet, P., S. Jagoueix, J. M. Bové, and M. Garnier. 1995. Detection and characterization of the African citrus greening liberobacter by amplification, cloning and sequencing of the $r p l \mathrm{KAJL}-r p o \mathrm{BC}$ operon. Curr. Microbiol. 30:137-141.

14. Sanger, F., S. Nicklen, and A. R. Coulson. 1977. DNA sequencing with chain-terminating inhibitors. Proc. Natl. Acad. Sci. USA 74:5463-5467.

15. Van Der Giessen, J. W. B., R. M. Harring, and B. A. M. Van Der Zeust. 1994. Comparison of the 23S ribosomal RNA genes and the spacer region between the 16S and 23S rRNA genes of the closely related Mycobacterium avium and Mycobacterium paratuberculosis and the fast-growing Mycobacterium phlei. Microbiology 140:1103-1108.

16. Villechanoux, S., M. Garnier, J. Renaudin, and J. M. Bové. 1992. Detection of several strains of the bacterium-like organism of citrus greening disease by DNA probes. Curr. Microbiol. 24:89-95.

17. Villechanoux, S., M. Garnier, F. Laigret, J. Renaudin, and J. M. Bové. 1993. The genome of the non-cultured, bacterial-like organism associated with citrus greening disease contains the mus G-rplKAJL-rpoBC gene cluster and the gene for a bacteriophage type DNA polymerase. Curr. Microbiol. 26: 161-166. 